\title{
Comparing International Student Friendship Networks in Buenos Aires: Direct Enrollment Programs vs. Study Abroad Centers
}

\section{Blake Hendrickson Ithaca College}

In March of 2011 U.S. president Barack Obama announced the "100,000 strong in the Americas" program during his visit to Chile (U.S. State Department, 2011). The initiative's goal is to reach 100,000 U.S. students studying in Latin America and 100,000 Latin American students studying in the United States. This interchange of students, knowledge, and ideas is viewed as a positive way to increase understanding between the two regions by means of building interpersonal ties between students who are billed as future leaders. Scholars in the intercultural relations and study abroad literature describe educational exchange between countries as an activity that instills tolerance in those who participate while converting them into potential bridges between cultures (Cushner \& Karim, 2004). Furthermore, a plethora of studies illustrate the positive personal transformations that students undergo while learning in different countries and cultures (Hadis, 2005). Thus, Obama's proposal for improving the often strained geo-political relationships between the regions through interpersonal contact is encouraging to say the least. However, as with any picture perfect plan there are potential flaws and caveats that policy makers must consider before declaring victory. The goal of this research is to examine the foremost problem underlying this student exchange plan and undermining its potential to build intercultural understanding. Simply stated, in all too many cases international students fail to establish friendships with local individuals (Brown, 2009a; Gareis, 2012; Neri \& Ville, 2008).

Scholars have observed a variety of reasons explaining why international students tend to lack interaction with host nationals and have difficulty developing friendships with them (Montgomery \& McDowell, 2009; Peacock \& Harrison, 2009; Trice, 2007). Cultural differences aside, researchers generally attribute responsibility to three separate entities: the international students, the host national students, and the university or study abroad program. The current research specifically focuses on the third entity by examining the relationship between study abroad program models and student friendship networks. In many cases institutions simply do not do enough to facilitate interaction between international students and host nationals (Brebner, 2008; Gareis, 2012; Peacock \& Harrison, 2009). Additionally, examining the complex nature of study abroad programs operating in different contexts is fundamental for understanding international and intercultural learning (Norris \& Dwyer, 2005; Rodman \& Merrill, 2010). Classification systems describing program differences in terms of learning contexts (Norris \& Dwyer, 2005) and immersion (Engle \& Engle, 2003) are widely acknowledged and the amount of contact with the local university and community that programs provide drive the study abroad debate (Rodman \& Merrill, 2010). The current 
investigation aims to provide a better understanding of study abroad organizational models in Buenos Aires and contribute to the immersion debate by comparing the friendship network composition of international undergraduate students directly enrolled at local universities, both from the U.S. and around the world, with students enrolled in study abroad center programs.

This investigation adopts Kim's (2001) cross-cultural adaptation theory, a comprehensive theory commonly applied by other researchers (Pitts, 2009; Tian \& Lowe, 2013). After conducting a comprehensive meta-analysis including 64 articles published in 29 journals of international student adjustment Zhang and Goodson (2011) commend its utility. Due to the nature of adaptation, Kim (2001) stresses the need for a longitudinal analysis that measures key variables such as one's relational networks. Thus, the current study uses a methodological research design that captures the friendship networks of international students at two points during their study abroad experience, at the beginning and end of the semester. This investigation begins with a brief history of the study abroad debate, a description of two program classification typologies, and a description of programs in Buenos Aires. This leads to a cross-cultural adaptation review and two hypotheses predicting relationships between study abroad contexts and friendship network composition. A description of the longitudinal mixed-method strategy and results that combine statistical analysis with in-depth interviews follows. The study ends with an explanation of the principal findings, limitations, and implications for study abroad programming.

\section{Study Abroad Program Models: A Debate}

This research examines a problem that is deeply rooted in the debate as to the best way to administer study abroad, a debate centered on the amount of contact that international students have with the host culture. In the early 1920s several U.S. universities developed study abroad programs for U.S. students in European universities (Hoffa, 2007). This type of programming was quite different from previous existing modes of study abroad which mostly involved individual students studying independently. In these programs, known as Junior Year Abroad (JYA), students took intense language courses upon arrival, lived with local host families, took courses at a local university or specialized courses for foreign students, attended various cultural activities, and went on short excursions out of the city and away from campus (Hoffa, 2007). These programs set a precedent in U.S. study abroad programming and made clear that full immersion, i.e., U.S. American students sitting in classrooms next to native students, was more an ideal than an achievable practice. In the 1960s study abroad administrators, university deans and presidents, international organization presidents, study abroad providers, and guest educators from a diverse array of countries held several conferences to discuss the "good" way to arrange the rapidly evolving study abroad industry (Hoffa, 2007).

The debate ranged from two opposite perspectives on how study abroad programming should be conducted. The traditionalists argued that the overseas academic experience should be controlled and resemble the domestic experience whose focus was on formal learning. The internationalists argued that the study abroad experience should expose students to cultural differences and give students the opportunity to compare and contrast values, thus placing importance on experiential learning (Hoffa, 2007). For the traditionalists the value of study abroad lies in the quality of academic courses as judged by U.S. academic standards. For the internationalists the value of study abroad lies in cross-cultural learning and its capacity to build peace and understanding between 
cultures. Proponents of each argument did not reject the other; rather the debate was on how to find a balance between the two.

Conference participants may not have agreed upon the best way to conduct study abroad, however they did come to general conclusions and present a typology of study abroad programs at the time. They recognized that the study abroad field was diverse, would likely continue to be in the future, and that programming could vary while still providing educational goals. They summarize these options according to duration of programs, placement in a four year program, relationship to academic institution in host country, selection of participants, leadership, and housing (Hoffa, 2007). Thus, one clear result of these conferences was the utility of organizing study abroad models into categories and/or typologies in order to visualize, understand, compare, and evaluate effectiveness. Due to the variance in study abroad contexts and program design, researchers have established an assortment of strategies and typologies for comparing programs.

In general, study abroad programs and universities are classified according to the extent to which they provide international students with housing options, classes, extra-curricular activities, and academic support. Additionally, comparative typologies consider the varying amount of interaction that students have with locals in these domains. For example, Norris and Dwyer (2005) define programs using a learning context continuum. On one end are "island" programs, selfcontained study centers that provide students who have little experience traveling the opportunity to study abroad without going too far out of their comfort zones. Those who choose these programs often study with students and faculty from their home university and tend to have fewer opportunities to interact with locals. In the middle of the continuum lie "hybrid" programs that offer and encourage students to take coursework at local universities as well as in their study center. Programs at the end of the continuum are termed "direct enrollment/full immersion" programs whereby international students take all classes in the foreign university with local students and professors while receiving support services from the local university's international office (Norris \& Dwyer, 2005). Norris and Dwyer found that, in terms of contact with the host culture, students in direct enrollment programs compared to hybrids were more likely to have made host national friends and maintained contact with them over time. On the other hand, other experts incorporating this continuum have provided valuable empirical data highlighting the effectiveness of "island" and "hybrid" models in achieving study abroad learning outcomes.

Vande Berg (2007) asserts that direct enrollment programs are good for those small numbers of students who adapt well to the challenges of living and learning in a new culture but fail to provide students with out-of-class support. Woolf (2007) argues that students need support and must be guided through their experience with analysis and retrospection. Guiding students through their intercultural experience provides them with more accurate perceptions of their own intercultural competence and less disengagement and confusion regarding their own cultural identity (Pedersen, 2009). Research comparing "hybrid" models providing this support with "direct enrollment" models suggests several drawbacks to the latter. One comprehensive study found that students studying with host nationals reported less intercultural learning than those who studied in classes with only U.S. students or mixtures of U.S., host culture, and other international students (Vande Berg, ConnorLinton, \& Paige, 2009). Another comparative study found that direct enrollment students were less likely than hybrid program students to acquire an appreciation for language learning and develop 
international careers (Norris \& Dwyer, 2005). Thus, these studies demonstrate the potential advantages inherent to study abroad centers.

Engle and Engle (2003) proposed another method for comparing study abroad learning contexts. They insist that focused and reflective interaction with the host culture distinguishes study abroad from traditional study and classify programs into five levels (Study tour; Short-term study; Cross-cultural contact; Cross-cultural encounter; Cross-cultural immersion) based on immersion into the host culture using seven indicators: duration of the stay, language competence, language of study, context of study, types of housing, provisions for structured cultural interaction, and guided reflection on experience. The authors propose this system as a way to better understand program differences and to give potential students a clearer idea of what to expect.

The two classification systems described above highlight the way in which differing program characteristics make an impact on the social networks that international students form in their new cultural environment and informed the program classification for the current study.

\section{Study Abroad Programs in Buenos Aires}

This investigation began with a series of in-depth interviews with university international education administrators and study abroad program directors in Buenos Aires. ${ }^{1}$ Interview results indicated that programs vary considerably in terms of the overall experience that their respective students have; however categorizing according to three types of administrative origin arose as the clearest way to analyze the distinct study abroad programs that participated in the current study. This categorization makes it possible to compare the experiences of U.S. and other international students in Buenos Aires.

The first types are study abroad offices operating in private universities in Buenos Aires who have agreements with foreign universities and study abroad institutes. In general the students arrive in Buenos Aires one to two weeks before classes start and begin the housing search. Students directly enroll in classes at the university and take classes side by side with local students and/or take classes specifically designed for international students. These programs have orientations and provide students with information concerning Buenos Aires, advise them on classes they should or should not take based on the experiences of past international students, assist students with the visa process, and provide support throughout the semester. Students also take Spanish language classes according to their Spanish level.

The second types are study abroad programs in the public university in Buenos Aires who have agreements with foreign universities or in some cases students enroll directly to the university. Students take regular courses with Argentines and there are no specialized or English language courses for international students. Each branch of the public university has an independent study abroad office that conforms to the needs of their international students. These programs are similar to the private universities in terms of orientation, academic counseling, and an independent housing search. The main difference between the private and public university has to do with the different

\footnotetext{
${ }^{1}$ The author conducted preliminary in-depth interviews with program directors in order to collect information regarding
} the specifics of study abroad in Buenos Aires and gain access to students. 
kind of experience that they offer and the amount of support that the program provides. Students in the public university generally have a more independent experience in which the institution offers minimal special accommodations for international students.

The third types are study abroad programs that would fall under the "branch campus" (Hoffa, 2007), "island" program, and/or "hybrid" program classification (Norris \& Dwyer, 2005; Vande Berg, Balkcum, Scheid \& Whalen, 2004). These programs are branches of U.S. universities or independent study abroad companies with study abroad centers in Buenos Aires. These particular programs place students in Argentine host families, although there are study centers and programs in Buenos Aires that offer other housing options. They study with other students from the U.S. and in some cases students from their home university. All students take Spanish language classes with other students from the U.S. and depending on their level take coursework in English and Spanish. In general, locally contracted professors give classes but students are otherwise separated from the Argentine university system. One "hybrid" program does give students the option to enroll in classes at their local partner universities. These programs organize several days of group orientation, group events, group excursions, and provide the students with a great deal of support. They have excellent facilities, including modern computer labs and classrooms, libraries, and lounge areas.

This research examines the influence that these distinct study abroad contexts have on the cross-cultural adaptation process, specifically focusing on friendship network formation and subsequent transformation over the course of a semester.

\section{Cross-Cultural Adaptation}

Kim (2001) defines cross-cultural adaptation as "the dynamic process by which individuals, upon relocating to new, unfamiliar, or changed cultural environments, establish (or reestablish) and maintain relatively stable, reciprocal, and functional relationships with those environments" (Kim, 2001 p. 31). Kim positions communication between the individual and the environment, at the heart of the process. Communication is one's participation in the interpersonal and mass communication activities of the host environment. Interpersonal communication activities are those everyday, faceto-face interactions that individuals have with others that offer personalized involvement with members of the host culture, while mass communication activities such as radio, television, magazines, newspapers, and advertising allow individuals to participate in the host culture from a macro perspective (Kim, 2001).

International students are inherently exposed to the new communication patterns, albeit at a superficial level, through interactions with locals at universities, shopping centers, restaurants, public transportation, museums, theatres, bars, clubs, sporting events, and libraries, as well as by observing local fashion and trends. In these contexts they have casual interactions with local professors, students, landlords, cashiers, taxi drivers, bus drivers, store clerks, servers, and ticket venders among dozens of other examples. Exposure to the new culture coupled with casual interpersonal interactions provides reference points for which students can compare and then adjust their own communication patterns and build host communication competence (Kim, 2001). However, this casual exposure and superficial interaction only scratches the surface of the communication patterns exhibited in another culture. International students largely rely on their newly formed interpersonal 
(intimate and acquaintance) friendship networks to better interpret their observations of exhibited communication behaviors.

\section{Friendship Networks}

In 1977 Bochner, McCleod, and Lin proposed a functional model for understanding the friendship patterns of international students and the specific function that each group serves. The first group is composed of co-nationals, or individuals from one's own country. The second group is composed of host-nationals, or individuals native to the country where the individual is studying. The third group is composed of multi-nationals, or individuals from other countries who are also studying abroad. The current study incorporates the functional model using a friendship network grid methodology in which students list all of their friendships and the nationality of those friends (Hendrickson, Rosen, \& Aune, 2011). This design gives a more comprehensive picture and illustrates not only how international student friendship networks emerge but also how they evolve over time. One common research finding is the prevalence and pervasiveness of co-nationals in an individual's friendship network.

Co-national friendships can serve as vital intimate bonds for international students and operate to enhance cultural learning (Bochner et al., 1977). Students discuss the new culture and exchange experiences with other students who are experiencing the same emotions (Woolf, 2007). These bonds also provide a feeling of cultural identity, offer emotional support (Maundeni, 2001), and give students the opportunity to relieve stress caused by culture shock (Kim, 2001). Often time immigrants and sojourners begin seeking these co-national contacts even before arriving in the new culture (Kim, 2001). Kim (2001) theorizes that co-national friendships may enhance the adaptation process in the short-term if those contacts have already advanced in their own adaptation. However, in the long-term, communication with co-nationals tends to impede adaptation as friendship formation with co-nationals likely reduces the opportunities for international students to form friendship with host nationals (Church, 1982). Additionally, friendship with co-nationals limits students' ability to acquire linguistic and cultural knowledge (Brown, 2009b) and spending less time with co-nationals has been linked to gains in intercultural learning (Vande Berg et al., 2009). Kim theorizes that extensive and prolonged participation in co-national communication activities hinders intercultural transformation and individuals who have acquired more communication competence in the host culture engage in less communication activities with co-nationals. Likewise, individuals who engage in more host national communication activities acquire more communication competence and experience more intercultural transformation. This theory is well supported.

The positive role, both psychologically and socially, that friendship with host nationals plays in the adaptation process is well established in the intercultural relations literature. These positive effects include more life satisfaction (Rohrlich \& Martin, 1991), more feelings of social connectedness, less homesickness (Hendrickson et al., 2011), less loneliness (Sawir, Marginson, Deumert, Nyland, \& Ramia, 2008), fewer social difficulties, improved communication competence (Ward \& Kennedy, 1993), and more positive feelings about the host culture (Pruitt, 1978). Kim's (2001) theory stresses the importance of having multiple interpersonal communication activities with individuals from the host country. Local contacts offer international students cultural information and resources they could not obtain from individuals from their own country or other international students. By forming friendships with those from the host country international 
students are able to gain insight into the minds and behaviors of local people and they begin to understand why people behave, communicate, and interact the way they do, thus previously unexplained behavior is put into context and can be interpreted more readily (Kim, 2001). Through interpersonal contact with host nationals international students learn the standards and underlying assumptions for both verbal and nonverbal communication, not to mention the host language. They learn what cultural values the new society stresses and what is socially approved or disapproved. Whether they realize it or not they rely on their social contacts to better interpret the various attributes and actions of others (Kim, 2001). Thus, increased interpersonal communication activities with host nationals are an indicator that an individual is adapting to the new culture. Kim's theory explicates how host national and co-national friendships influence the adaptation process. The third group identified in the functional model is multi-national friendships.

Although most studies show that international students tend to have friendship networks mostly composed of co-nationals (Bochner et al. 1977; Brown, 2009b; Furnham \& Alibhai, 1985; Maundeni, 2001; Neri \& Ville, 2008; Pruitt, 1978; Sudweeks, Gudykunst, Ting-Toomey, \& Nishida, 1990; Trice \& Elliot, 1993; Ying, 2002), some exceptions to this trend exist; studies have found that the majority of friendships were with host nationals (Hendrickson et al., 2011) and/or multinationals (Bochner, Hutnik, \& Furnham 1985). According to the functional model, multi-national friends serve as companions for non-task oriented, recreational activities (Bochner et al, 1977). When international students arrive in a new place they begin to build their social networks, they often do this by making friends with other international students, others who may feel lost and looking for new friends. Furthermore, unlike co-nationals, multi-national friends present the possibility for language acquisition to occur. This is especially the case for Europeans or U.S. Americans who build friendships with non-Argentine Latin Americans and/or Spaniards in Buenos Aires.

The functional model is useful for understanding the role that each friendship group plays in the complete friendship network. The next section outlines the cultural environment dimension of Kim's (2001) theory and positions the study abroad program context in her theoretical framework

\section{Cultural Environment}

Kim (2001) identifies three significant environmental conditions that influence the crosscultural adaptation process and friendship network formation. The pressure to conform exerted by Argentinean society on international students, the receptivity of Argentinean society toward international students, and the strength of each student's own ethnic group within the new environment (Kim, 2001). The first two elements focus primarily on characteristics of Argentine and Buenos Aires society. The third element, ethnic group strength focuses on characteristics of international students, their institutions, and the study abroad context.

Ethnic group strength is the relative status and power that membership in an ethnic group accords. One element of ethnic group strength that Kim (2001) discusses is institutional completeness. This element is related to the extent that a group has organized and established its own economic, political, social, and cultural systems. Kim suggests that the more a group has established its own institutions the less individuals must rely on host culture institutions, thus essentially impeding adaptation. Students studying at study abroad centers enjoy many institutional 
and academic similarities (e.g., academic calendar, grading scale, technological resources). Another element of ethnic group strength is identity politics whereby group members pressure other members to stick to the group and criticize those who separate and interact with locals. Thus, strangers facing strong in-group pressure may be discouraged from learning the host language and culture (Kim, 2001).

Considering the nature of distinct study abroad learning contexts, Kim's (2001) theory describing the interplay between co-national and host national friends, and the potential role that cultural environment factors of institutional completeness and identity politics play in the friendship network formation process the following hypotheses are posed.

H1: International students enrolled in study abroad centers will report more co-national friends at the beginning and end of the semester than international students directly enrolled in Argentine Public and Private Universities.

H2: International students enrolled in Argentine Public and Private Universities will report more host national friends upon arrival and at the end of the semester than students in study abroad centers.

\section{Methodology}

Mixed-Method Longitudinal Design

This investigation employs a mixed-method longitudinal design using a quantitative survey assessing the same participants on two separate occasions. The main objectives of longitudinal research are to analyze patterns of change and to better explain the magnitude of causality (Menard, 2002). Several scholars analyzing the experiences of individuals crossing cultures emphasize the use of longitudinal research design (Church, 1982; Kim, 2001; Zhang \& Goodson, 2011) and encourage the use of in-depth interviews in order to provide more contextual information (Church, 1982; Kim, 2001). When conducting mixed-method research the sampling procedure is particularly important considering that sampling characteristics for quantitative and qualitative research are dichotomously different (Teddlie \& Yu, 2007). Consequently, this research employs a Sequential Mixed-Method Sampling Procedure (Teddlie \& Yu, 2007). In this case, a QUAL-QUAN-QUAL sequence. First, this study used qualitative, purposive sampling to select university and study abroad programs. Second, it incorporated probability, self-selecting sampling in order to get a representative sample of international students from each university. Third, it used purposive sampling that selects only those international students who participated in the quantitative survey.

\section{Participants}

International students affiliated with ten (four private, three public, three study abroad centers) universities and/or study abroad centers received an email two weeks after the beginning of classes from their respective institutions requesting their participation in a research project. The most up-todate numbers come from a $2008 \mathrm{ArgEdu}$ research report which estimated that 25,000 international students arrived in Argentina for undergraduate, postgraduate, and study abroad programs (Giavi, Iglesia, \& Iglesia, 2008). In a 2013 BBC news article authorities reported that there were approximately 50,000 international students in Argentina (Smink, 2013). Given that these numbers speak for Argentina as a country it is difficult to measure the exact number of international students 
in Buenos Aires considering that many students registered with the immigration authorities study outside of Buenos Aires, and not all students in Buenos Aires are registered with the immigration authorities as international students. Thus, the following numbers for total international students from each university are approximations and include students that may be completing their whole degree.

Private University 1 reported 300 international students and 22 participated in this study. Private University 2 reported 135 international students and 12 participated. Private University 3 reported 200 international students and 9 participated. Private University 4 reported 190 international students and 26 participated. Public University 1 reported 37 international students and two participated. Public University 2 reported 80 international students and two participated. Public University 3 reported 200 international students and five participated. Study Abroad Center 1 reported 120 students and 14 participated. Study Abroad Center 2 reported 61 international students and six participated. Study Abroad Center 3 reported 35 international students and seven participated.

Thus, from these numbers it can be estimated that across the ten programs or universities, approximately 1000 to 1400 international students received an email request to participate in the present study. A total of 105 of those students participated in both phases, including 69 participants affiliated with a private university, nine affiliated with a public university, and 27 primarily affiliated with a study abroad center. Thus, this sample does achieve the first sampling objective, which was to obtain $10 \%$ of the students studying in those universities that participated. However, this investigation did not fully achieve the second sampling objective, which was to obtain 25 students from each study abroad context. In this case the private university and study abroad center program samples are sufficient; however only nine students from the public university participated. Subsequently, this research presents sub-sample comparative findings, but cannot draw any strong conclusions regarding the public university.

146 students voluntarily completed the online survey in Spanish or English two weeks after beginning classes, however several failed to participate again two weeks before classes finished, leaving a sample consisting of 105 international students. 81 (77\%) were female and $24(23 \%)$ were male. This ratio of female to male participants is not alarming as research shows that a higher ratio, nearly two to one, of females to males choose to study abroad due to various factors (Salisbury, Paulsen, \& Pascarella, 2010). Participants also reported an average age of $22(S D=2.64)$ years at the end of the semester. Additionally, non-native Spanish speakers reported their own perceived language proficiency by answering two questions; 1) How much difficulty do you have understanding spoken Spanish? 2) How much difficulty do you have speaking Spanish? on a seven point Likert-type scale ranging from 1 (extreme difficulty) to 7 (no difficulty). An independent samples ttest showed no significant difference in perceived language proficiency $t(86)=1.11, p=.28$ between study abroad centers $(M=4.42, S D=1.16)$ and Argentine private \& public universities $(M=4.75$, $S D=1.31)$.

The participants came from 20 different countries: 46 (44\%) from Europe (16 Germany, ten France, eight Spain, three Austria, two Finland, one from Italy, Netherlands, Norway, Portugal, Czech Republic, Switzerland, Sweden, respectively), 45 (43\%) from North America (43 U.S., two 
Canada), twelve (11\%) from Latin America (five Brazil, three Colombia, three Mexico, one Chile), one from Morocco, and one from India. Table 1 presents between university/program demographic information including region, age, and university education completed at the beginning of the semester.

Table 1. Participant Demographics Across University

\begin{tabular}{lllllll}
\hline & \multicolumn{3}{c}{ Participants } & & & \multicolumn{2}{c}{$\begin{array}{l}\text { Semesters } \\
\text { Age }\end{array}$} & & $\begin{array}{l}\text { Completed } \\
\text { M (SD) }\end{array}$ \\
\cline { 2 - 5 } & Total & N. America & Europe & L. America & M (SD) & M (SD) \\
\hline Private & 69 & 18 & 42 & 9 & $22(2.73)$ & $5(22)$ \\
Public & 9 & 1 & 5 & 3 & $24(3.26)$ & $6(3.46)$ \\
Study Center & 27 & 27 & 0 & 0 & $20(.58)$ & $4(1.25)$ \\
\hline
\end{tabular}

The researcher interviewed 35 of those international students who completed the quantitative survey. The mean interview length was one hour and 13 minutes ( $S D=15$ minutes). Out of those interviewed only one failed to participate in the second phase of the quantitative survey, leaving the total number of interviews at 34. There were 23 females and eleven males with an average age of 22 $(S D=2.52)$ years. 20 interviewees studied at private universities, four studied at public universities, and ten were part of study abroad centers. Interviewees came from 13 different countries: 14 (41\%) from Europe, 15 (44\%) from North America (14 U.S., one Canada), and five (15\%) from Latin America. Thus, in terms of regional origin the 34 students interviewed represent a sample nearly proportionate to the larger sample that completed the online survey. The researcher interviewed participants in Spanish and English. Given the option, 29 chose Spanish and six chose English. See Appendix for interviewee reference list.

\section{Friendship Network Grid}

Hendrickson et al.'s (2011) friendship network grid asks participants to list all their friends in Buenos Aires and indicate where they are from. Social science researchers have used this method for collecting and analyzing relationship data since the 1960s (Wasserman \& Faust, 1994) and its general reliability is validated by a plethora of sociological and anthropological findings (Rogers \& Kinkaid, 1981). Social network analysis paints a bigger picture and helps explain the relationships between one's social contacts and other variables. Additionally, educational researchers encourage the use of social network analysis in conjunction with a longitudinal design in order to track processes over time (Rienties, Nanclares, Jindal-Snape, \& Alcott, 2013).

\section{In-depth interviews}

The objective of the in-depth interviews was to extract contextual data, specifically focusing on friendship networks and University/Study abroad programs as well as other pertinent information provided by students but not related to those specific variables. The researcher listened to each interview and recorded participant answers to questions under each variable using an Excel spreadsheet. This coding procedure made it possible to consult and analyze each participant in terms of specific variables. This technique represents several of the classic sets of analytic moves described by Miles and Huberman (1994). 


\section{Confound Checks}

The main goal of this research is to capture friendship networks at two points, shortly after arriving in Buenos Aires and shortly before finishing the semester. Due to the diversity of programs several problems arose during the data collection process that deserve attention. First, the majority (78 students, $74 \%$ of sample) who participated in this study reported to be studying in Buenos Aires for one semester. However, 19 students planned on studying for two semesters and seven planned on staying for more than two semesters. Additionally, participants did not indicate their university status, only the total amount of university semesters completed $(M=5, S D=2.23, M d n=4$, Mode=4) at the beginning of the semester. The central tendency measures for semesters completed indicate that the majority were undergraduate students. However, 14 participants had completed eight or more semesters upon arrival in Buenos Aires suggesting graduate student status in their respective countries. Students studying more than one semester and graduate students potentially have different expectations regarding friendship, however their data is included to ensure a sufficient sample size.

Second, study abroad directors invited all international students associated with their programs to participate, which resulted in some students participating after already having completed one semester. Three students completed the quantitative survey at the beginning and end of their second semester in Buenos Aires. These discrepancies directly affect the longitudinal variables and are not included in the analysis. After dropping these three cases students completed the first quantitative survey 4.9 weeks after arriving in Buenos Aires and the second survey 18.6 weeks after arriving. In other words a time frame of approximately 13.7 weeks or 3.5 months elapsed between the first and second phases.

Third, survey comprehension was potentially a problem for those students whose first language is neither Spanish nor English. In order to control for this confound students answered the question "English/Spanish may not be your first language so some of the previous questions may not have been clear. Please indicate the number that best indicates your understanding of the questions asked on this survey" on a Likert-type scale ranging from 1 (did not understand anything) to 7 (completely understood everything). Students reported high survey comprehension at the beginning 6.86 (SD=.47) and end $6.92(S D=.27)$ of the semester, thus giving confidence that students understood the questions on the survey.

\section{Results}

This study proposed that students at study abroad centers would report significantly more conational friends while students enrolled in Argentine private and public universities would report more host national friends. No specific hypotheses or research questions regarding multi-national friendships were posed; however due to their prevalence in overall friendship networks these finding are included in the results. Statistical analyses demonstrate several significant differences in friendship network composition between the three university settings shortly after students arrived and at the end of the semester. See Table 2 for both time 1 and time 2 co-national, multi-national, and host national friendship totals between university settings. This analysis presents the data for all three groups, however cautions the reader in making any concrete conclusions related to significant public university findings. 
Blake Hendrickson

Table 2. Friendship Totals Across University Setting

\begin{tabular}{lcllllll}
\hline $\begin{array}{l}\text { University } \\
\text { Type }\end{array}$ & $\mathrm{N}$ & $\begin{array}{l}\text { Co-Nat } \\
\text { (Arr) }\end{array}$ & $\begin{array}{l}\text { Co-Nat } \\
\text { (Dep) }\end{array}$ & $\begin{array}{l}\text { Multi-Nat } \\
\text { (Arr) }\end{array}$ & $\begin{array}{l}\text { Multi-Nat } \\
\text { (Dep) }\end{array}$ & $\begin{array}{l}\text { Host Nat } \\
\text { (Arr) }\end{array}$ & $\begin{array}{l}\text { Host Nat } \\
\text { (Dep) }\end{array}$ \\
\hline Private & 67 & 6.0 & 6.8 & 6.9 & 8.8 & 4.3 & 5.9 \\
Public & 8 & 6.6 & 4.1 & 10.4 & 14.6 & 8.7 & 9.5 \\
Study Center & 27 & 12.6 & 10.4 & 1.4 & 1.7 & 3.0 & 4.6 \\
\hline
\end{tabular}

First, one-way ANOVAs revealed a significant difference between the three university settings for co-national $F(2,98)=15.15, p=.00, \eta^{2}=.24$, multi-national $F(2,98)=16.28, p=.00, \eta^{2}=.25$, and host national friends $F(2,98)=3.9, p=.02, \eta^{2}=.07$ at the beginning of the semester. The ANOVA test only illustrates that there is a significant difference between university settings, but does not specify which university settings were significantly different from each other. Thus, an additional analysis, the Tukey Post Hoc test was run. This analysis revealed that students studying in study abroad centers $(M=12.59,95 \%$ CI $[10,15])$ had significantly more co-national friends than those studying at public universities $(M=6.57,95 \%$ CI $[1.2,11.9]), p=.02$ and private universities $(M=6.01,95 \%$ CI $[4.9,7.2]), p=.00$; that students studying in study abroad centers $(M=1.44,95 \%$ CI $[.8,2.1])$ had significantly less multi-national friends than those studying at public universities $(M$ $=10.43,95 \%$ CI $[4.5,16.4]), p=.00$ and private universities $(M=6.87,95 \%$ CI $[5.6,8.2]), p=.00$; and that students studying in study abroad centers $(M=3.04,95 \%$ CI $[1.32,4.76])$ had significantly less host-national friends than those studying at public universities $(M=8.71,95 \%$ CI $[3.2,14]), p=$ .02 .

Second, one-way ANOVAs at the end of the semester also showed that there was a significant difference between the three university settings for co-national friends $F(2,99)=4.8, p=.01, \eta^{2}=$ .09 and multi-national friends $F(2,99)=15.41, p=.00, \eta^{2}=.24$, but not for host national friends $F(2,99)=2.13, p=.12, \eta^{2}=.04$. Tukey Post Hoc tests revealed that students studying in study abroad centers $(M=10.41,95 \%$ CI $[8.3,12.5])$ still had significantly more co-national friends than those studying at public universities $(M=4.13,95 \%$ CI $[1.8,6.5]) p=.03$ and private universities $(M$ $=6.81,95 \%$ CI $[5.2,8.4]) p=.03$ and that students studying in study abroad centers $(M=1.7,95 \%$ CI $[.95,2.5])$ still had significantly less multi-national friends than those studying at public universities $(M=14.63,95 \%$ CI $[4.2,25]), p=.00$ and private universities $(M=8.79,95 \%$ CI $[7$, $10.5]), p=.00$.

It is important to note that some students listed up to 50 friends while others listed as few as three friends. Consequently, this analysis includes friendship ratios in order to better understand overall friendship networks and to more accurately compare these networks across university settings.

First, one-way ANOVAs showed that upon arrival there was a significant difference between the three university settings for co-national ratios $F(2,98)=40.23, p=.00, \eta^{2}=.45$, multi-national ratios $F(2,98)=24.29, p=.00, \eta^{2}=.33$, and host national ratios $F(2,98)=6.97, p=.00, \eta^{2}=.12$. Tukey Post Hoc tests for friendship ratios revealed the same trends as with friendship totals, 
students studying in study abroad centers $(M=.77,95 \%$ CI $[.70, .84])$ had a significantly higher ratio of co-national friends than those studying at public universities $(M=.21,95 \%$ CI $[.09, .33]), p=.00$ and private universities $(M=.37,95 \%$ CI $[.31, .42]), p=.00$; that students studying in study abroad centers $(M=.08,95 \%$ CI $[.05, .12])$ had a significantly lower ratio of multi-national friends than those studying at public universities $(M=.41,95 \%$ CI $[.24, .57]), p=.00$ and private universities $(M$ $=.40,95 \%$ CI $[.34, .45]), p=.00$; and that students studying in study abroad centers $(M=.77,95 \%$ CI $[.70, .84])$ had a significantly lower ratio of host-national friends than those studying at public universities $(M=.39,95 \%$ CI $[.18, .60]), p=.00$ and for private universities as well $(M=.24,95 \%$ CI $[.20, .28]), p=.04$. Table 3 illustrates friendship network ratios.

Table 3. Friendship Ratios Across University Setting

\begin{tabular}{lcllllll}
\hline $\begin{array}{l}\text { University } \\
\text { Type }\end{array}$ & $\mathrm{N}$ & $\begin{array}{l}\text { Co-Nat } \\
\text { Ratio } \\
\text { (Arr) }\end{array}$ & $\begin{array}{l}\text { Co-Nat } \\
\text { Ratio } \\
\text { (Dep) }\end{array}$ & $\begin{array}{l}\text { Multi-Nat } \\
\text { Ratio (Arr) }\end{array}$ & $\begin{array}{l}\text { Multi-Nat } \\
\text { Ratio (Dep) }\end{array}$ & $\begin{array}{l}\text { Host-Nat } \\
\text { Ratio (Arr) }\end{array}$ & $\begin{array}{l}\text { Host Nat } \\
\text { Ratio (Dep) }\end{array}$ \\
\hline Private & 67 & $36 \%$ & $32 \%$ & $40 \%$ & $40 \%$ & $24 \%$ & $28 \%$ \\
Public & 8 & $21 \%$ & $13 \%$ & $41 \%$ & $55 \%$ & $39 \%$ & $32 \%$ \\
Study Center & 27 & $77 \%$ & $68 \%$ & $8 \%$ & $10 \%$ & $15 \%$ & $22 \%$ \\
\hline
\end{tabular}

Second, one-way ANOVAs at the end of the semester showed the same significant differences for friendship ratios as for friendship totals. There was a significant difference between the three university settings for co-national ratios $F(2,99)=33.16, p=.00, \eta^{2}=.40$ and multi-national ratios $F(2,99)=21.76, p=.00, \eta^{2}=.31$, but not for host national friendship ratios $F(2,99)=1.26, p=$ $.29, \eta^{2}=.02$. Finally, Tukey Post Hoc tests for friendship ratios at the end of the semester revealed the same trends as with friendship totals. Students studying in study abroad centers $(M=.68,95 \%$ CI $[.60, .76])$ still had a significantly higher ratio of co-national friends than those studying at public universities $(M=.13,95 \%$ CI $[.08, .19]), p=.00$ and private universities $(M=.32,95 \%$ CI $[.26, .37])$, $p=.00$ and that students studying in study abroad programs $(M=.10,95 \%$ CI $[.06, .14])$ still had a significantly lower ratio of multi-national friends than those studying at public universities $(M=.55$, $95 \%$ CI $[.36, .74]), p=.00$ and private universities $(M=.40,95 \%$ CI $[.34, .47]), p=.00$. However students studying in study abroad centers $(M=.22,95 \%$ CI $[.14, .30])$ no longer had a significantly lower ratio of host-national friends than those studying at public universities $(M=.32,95 \%$ CI $[.14$, $.49]), p=.41$. Thus, the additional friendship ratio analysis demonstrated that friendship network ratios across university settings were similar to friendship totals.

Analyzing friendship totals and friendship network ratios illustrates three general trends concerning different university settings and friendship networks. First, students who study at study abroad centers have significantly more co-national friends shortly after classes begin and at the end of the semester than students who study at Argentine private and public universities. Second, students who study at Argentine private and public universities have significantly more multinational friends shortly after classes begin and at the end of the semester than students studying at study abroad centers. Third, students studying at study abroad centers have significantly fewer host 
national friends than students studying at Private and Public universities at the beginning of the semester, however this difference is no longer significant at the end of the semester.

During in-depth interviews students from the three different university settings described their friendship networks. A U.S. student at a study abroad center reflected upon his friendships and stated (Ref 29):

\section{The big majority of my friends are from the program, my core friends are those that I met during the first} week.

This specific program is well organized. The majority of students arrive at the airport together, however one girl said she arrived in Buenos Aires a few days early and then went to the airport to meet up with the group (Ref 28). The coordinators then take the group to an "estancia" outside of Buenos Aires for three nights where the students have a group orientation, get to know each other, and learn to navigate the city (Refs 28, 29, 30, 31). After the initial orientation at the estancia students spent a night together at a hotel in Buenos Aires. The following day they did a drop off activity where small groups had to find their way back to the program headquarters from various points in the city. After four days and nights together their homestay families picked them up (Refs $28,29,30,31)$.

These first encounters and initial days in Buenos Aires were influential in the friendship network formation for these students. All of the students interviewed recalled meeting their best friends in Buenos Aires for the first time at the airport or before arriving (Refs 28, 29, 30, 31) and although not every student reported positive first impressions, the extended time together allowed them to grow closer. Another U.S. student in the same program described her best friend in Buenos Aires and when they met (Ref 30):

We have a Facebook group that started before we got down here and I hit it off online with one of the girls in our program. Then she happened to be sitting by me on the same flight to Buenos Aires.

Students enrolled in these programs not only meet and get to know each upon arriving they have continued extended contact throughout the semester. They have the majority of their classes together and go on group trips to other regions of Argentina. They have private buses and stay in the same hotels. Thus, students build very tight bonds with each other that potentially hinder their ability to make friends with other people. A student in a study abroad center reflected on this group dynamic (Ref 28):

It's interesting because we're together all the time, the friendships evolve and small groups form within the big group. I'm part of the group, for the first month and a half I was more connected to the others, we did everything together. But after that I decided to get away from the group a little, I said to myself, I need to meet other people. But, it's not easy to get away, everyday there's a guy in our group very focused on the group doing activities together, always screaming at us for not wanting to do things with the group.

These comments represent the identity politics element described by Kim (2001) and suggest that students feel pressure to stick to their own group. In-depth interviews with students at study abroad centers highlight the impact that the co-national group dynamic played on their friendship networks. International students in Argentine private and public universities also discussed group 
dynamics (Ref $1,2,11,14,20)$, but tended to focus on multi-national groups infiltrated with local Argentines. A German student stated (Ref 5):

Many of my friends are international students, not Argentines, but Spanish speakers from Chile, Ecuador, Uruguay (...) I also have some Argentine friends

Finally, a student enrolled in a study abroad center who took one course in the public university, one course in the private university, and two courses at the program study center compared his experiences in all three contexts. His multiple context perspective led to the question, "If you could choose to study directly at the university or with this program what would you prefer?” (Ref 19):

That's a difficult question... I like that the program helps us a lot organizing classes and offers support with our lives here in general. However, we're not really foreign students, we're students in an exchange program and we don't have much contact with traditional students, I don't like that part. I can't complain because they take really good care of us.

\section{Discussion}

Results from this study demonstrate the key role that the study abroad context plays in international student friendship network formation. Students in study abroad centers have significantly more friendships with individuals from their own country, significantly fewer local friendships upon arrival, and significantly fewer friendships with individuals from other countries than those studying in Argentine private and public universities. This finding is relevant to one of the central debates concerning study abroad organization and administration, one that centers on immersion and time that students spend communicating with host culture individuals. The ensuing discussion includes four explanations for the prevalence of study abroad centers, three administrative possibilities that could potentially modify the current trend, and several research limitations that provide directions for future research.

\section{Four Explanations for Study Abroad Centers}

The current research suggests four main themes explaining study abroad center administration in Buenos Aires. First, an analysis of the history of the U.S. study abroad industry reveals that the basic structure, albeit more advanced and sophisticated today, has essentially changed little in terms of interaction with the host culture over the past 100 years. Second, the study abroad center model circumvents organizational obstructions present during international education endeavors. Third, this structure effectively allows more U.S. students to study abroad, specifically those who do not possess adequate language skills and/or cultural knowledge. Fourth, the existence of study abroad centers illustrates the general ethnocentric attitude embedded in the U.S. academic system.

The first study abroad programs arose in the 1920s, followed by branch campuses and consortium agreements in the 1950s (Hoffa, 2007). Although many of the academic principles have evolved the basic contact that students have with the local culture remain the same. U.S. students take specialized courses and intensive language classes with each other in foreign countries while participating in group excursions to selected sites near the place of study. This is the case with all three study abroad centers that participated in the current research and several other programs in Buenos Aires that the author is familiar with. Woolf (2007) supports this model arguing that U.S. students learn best under guided situations and that immersion into foreign campuses is not ideal. 
Pederson (2009) provides empirical evidence supporting her argument that through guided learning students acquire more intercultural competencies. Indeed, once an individual has learned to learn in a certain way it is difficult to go overseas and learn in a different way (Hall, 1959). Furthermore, this historical model offers advantages and practical benefits to universities, administrators, and students (Goldstein, 2015). However, in terms of friendship networks, findings from the current study demonstrate that this model, intentionally or not, directs students into co-national groups and inhibits their ability to develop meaningful host national and/or multi-national friendships. Students in study abroad center programs reported an average of twelve co-national friends upon arrival while students studying directly at Argentine universities reported an average of six. The model forces students into a group dynamic that they can easily mold to, or if they choose, fight to avoid. However, it is difficult to not form friendships with individuals who you see and spend a considerable amount of time with every day. Savicki (2010) suggests that it is more functional to rearrange study abroad programming than to blame students for retreating into U.S. American groups.

The second explanation for this study abroad model is related to the nature of organizations. Instead of working with universities in other countries study abroad centers have created their own institutions, thus evading organizational barriers. One of the most prominent factors shaping the academic profession and universities is the national context (Clark, 1986). Clark (1986) describes starkly different organizational models between universities in the United Kingdom, France, Germany, and the United States, although in all countries universities are divided by disciplines that inherently position themselves in a hierarchy. Additionally, countries differentiate in terms of who is in charge of the universities' administrative tasks. Universities require bureaucracies with an administration that is highly professionalized and some countries do not satisfy this necessity, as they are plagued with administrators who have insufficient preparation to manage their tasks effectively (Nogueira \& Góngora, 2000). These national differences in university organization certainly make international education and study abroad administration an arduous undertaking. The organizational structure of study abroad centers diminishes problems related to administrative tasks such as transferring credits, financial aid, and the visa process, along with the sensitive issue of student security abroad. In any case, organizational necessities directly affect the study abroad experience and results from this investigation highlight this reality.

Third, study abroad centers enable students with inadequate language abilities to study abroad. The reality is that in order to directly study, or more specifically, take classes alongside Argentines at an Argentine university, students must be able to speak Spanish at a relatively high level. Study abroad centers are attractive because they offer U.S. students the opportunity to spend part of their undergraduate career abroad without having a high level in the target language. However, findings from this study demonstrate that international students who study at Argentine universities have more Argentine and multi-national friends than students in study abroad centers. Additionally, during in-depth interviews a student in a study abroad center reported his desire to study directly at the university (Ref 29). This comment is consistent with a recent hypothetical preference study in which the majority of students chose a more immersive study abroad context over an exported US campus (Goldstein, 2015). In short, study abroad centers are a potential disservice for the most capable students with adequate language skills, while those who prefer a more immersive experience miss the opportunity to study directly at Argentine universities. 
Fourth, the first three explanations for why U.S. study abroad programs are structured in such a way are essentially reflections of the practical nature of U.S. culture and institutions. Regardless of these logical and practical reasons, this structure largely reflects U.S. anthropologist Edward T. Hall's cultural writings, he states: "Americans in particular have too long assumed that the U.S. educational system represents the ultimate in evolution and that other systems are less advanced than our own" (Hall, 1959, p. 49). The reality is that western social science is plagued with bias, with the majority of ideas and concepts coming from European and U.S. educational traditions (Wiarda, 1981), as well as publication standards (Saavedra, 2012). International business researchers use the term "institutional ethnocentrism" to describe U.S. firms that promote the home culture's way of doing things by imposing structures, processes, and management mentalities on overseas affiliates (Johnson, Lenartowicz, \& Apud, 2006). This ethnocentric attitude is arguably heightened in relation to Latin America. McPherson (2006) describes the historical U.S. imagination of Latin America as a world "perpetually unable to achieve stability and prosperity without the help of a 'higher' civilization such as that of the United States" (p. 9). To be fair, this attitude has likely diminished since the late 1800s and certainly was not and is not shared by everyone. However, study abroad centers in Latin America and other regions of the world give the impression that the U.S. educational system is superior and the mindset that although it is important and desirable for students to study abroad and learn about other cultures, it is better if students do so in a system, guided, controlled, and micromanaged from the United States. One potential way for other ideas, methodologies, and practices to disperse is through study abroad, however few students are directly exposed to these different systems because the U.S. academic structure dominates, even when students "study" in Latin America.

This discussion offered four explanations for current U.S. study abroad industry organization. These explanations provide the historical, organizational, and practical context. The subsequent section takes these explanations into consideration while presenting several implications this research has for study abroad as well directions for future research.

\section{Implications for U.S. Study Abroad}

One proven way to promote international student movement is through bilateral agreements (Fernández, Fernández, \& Vaquero, 2007). This would give U.S. students more options to study directly at Argentine universities. This would also benefit Argentine and other host country programs and initiatives. For example, in 2006 the Argentine Ministry of Education created the Program for the Promotion of the Argentine University with one of its main objections being an increase in the amount of international students in Argentina (MEA, 2010). Furthermore, the city of Buenos Aires sees the arrival of international students as an opportunity to not only share its dynamic culture but also its social and academic life (Giavi et al., 2008). Thus, an influx of U.S. students studying at Argentine universities is both welcomed and encouraged.

Second, when students study abroad through study abroad center programs or under bilateral university agreements they are generally eligible for federal student loans. However, if a student wants to directly enroll in a foreign University, which would be a more economical option at Argentine universities and for most Latin American universities in general, in most cases they are not eligible for federal student loans. Currently (2016-2017) 409 foreign universities are part of the U.S. federal student loans program, i.e. students may enroll directly and receive federal loans. The 
majority of them are in Canada, the United Kingdom, and Australia. There is a selection of universities in Latin America, including eight in México, five in the Dominican Republic, four in the Caribbean, one in Costa Rica, and one in Argentina ${ }^{2}$ (U.S. Department of Education, 2016). Other than the recent addition of the Universidad Torcuato di Tella in Buenos Aires, universities in South America do not participate in the federal loans program. Thus, if a U.S. student wants to enroll directly they are neither eligible to receive federal student loans nor eligible for in-school deferment on already existing loans. Thus, the federal government gives little incentive for students who wish to study abroad independently in South America.

Third, along with making student loans more accessible for students to study independently, U.S. universities and their respective study abroad offices could not only give students the option of studying at local campuses but to also encourage this practice and to give incentives for those students who do directly enroll. Incentives could come in the form of more flexibility in terms of accepting transfer credits from foreign universities or direct foreign enrollment scholarships.

\section{Limitations \& Directions for Future Research}

The objective of this investigation was to compare the international student experience in distinct study abroad contexts and to better understand the cross-cultural adaptation process. The public university was treated as an independent variable in the program comparison analysis, however due to the small number $(n=9)$ of participants no concrete conclusions can be statistically inferred. This information would be useful for foreign universities and study abroad programs looking to make international agreements with universities in Argentina. It would also be beneficial for Argentine study abroad administrators interested in better understanding the intricacies of the industry in Argentina.

Additionally, there is certainly an ideological debate in Argentina and other countries as to the value of both public and private universities (Saavedra, 2012). Results from study abroad director interviews and student interviews suggest that students at the public university are more independent than those at the private university, moreover the quantitative survey data indicate that students at the public university not only had more host national friends but also tended to be older, had completed more semesters of university education, and in some cases were graduate students in their home countries. However, due to the small sample, the magnitude of these differences and their influence on host national friendship formation is not clear. Future investigations aimed at understanding these distinctions are necessary considering the tendency for international students to study at Argentine private universities, despite the fact that three of the top five ranked universities in Argentina are public (QS, 2015).

This research did allow for fruitful comparisons between the private university and study abroad centers. However, they are limited to the overall study abroad context, despite important distinctions

\footnotetext{
2 México: Centro de Estudios Universitarios, CETYS Universidad, Instituto Tecnológico de Monterrey, Universidad de La Salle Bajío, Universidad de Guanajuato, Universidad de Monterrey Nuevo León, Universidad Autónoma de Guadalajara, Universidad del Noreste. Dominican Republic: Instituto Tecnológico de Santo Domingo, Pontificia Universidad Católica Madre y Maestra, Universidad Central del Este, Universidad Iberoamericana, Universidad Nordestana San Francisco de Macorís. Caribbean: American University of the Caribbean School of Medicine, American University of Antigua, Medical University of the Americas, St. George's University. Costa Rica: Universidad de Iberoamérica. Argentina: Universidad Torcuato di Tella.
} 
between each programs' offerings. The three study abroad centers in the study included a U.S. "branch" campus, a traditional "island" program, and a "hybrid" program. Larger sample sizes from each institution would have also presented the opportunity to compare between universities and between study abroad centers. This information would be useful for study abroad administrators in both private universities and study centers looking to compare their specific program specifics with those using similar models. In his 1960s writing history professor and study abroad specialist Irwin Abrams stated, "any program that does not find ways to provide meaningful cross-cultural encounters with the host culture fails its students" (Hoffa, 2007, p. 282). The growth of the study abroad industry calls for more research examining the programming that aims to facilitate interaction with host nationals.

\section{Conclusion}

This research argues that the study abroad context plays an influencing role in the friendship networks and cross-cultural adaptation of international students in Buenos Aires and defines the experience that students have in another culture. Study abroad centers circumvent the complexity of national university contexts and cater to the specific needs of U.S. American students. A strong argument exists that these models are better because the majority of U.S. American students just cannot do it on their own (Vande Berg, 2007); however findings from this research highlight their inherent drawback. Complete immersion into an unfamiliar university setting may not be the answer; however complete isolation from local universities and students should also not be the norm. Findings from this investigation demonstrate that students who study abroad at study abroad centers have an overwhelming amount of contact with co-nationals resulting in less meaningful contact with host culture individuals. Very few study abroad professionals would deny the importance of developing host national relationships, however facilitating these relationships often gets lost in the shuffle of complex university organization, historical pretexts, and practicality.

\section{References}

Bochner, S., Hutnik, N., \& Furnham, A. (1985). The friendship patterns of overseas and host students in an Oxford student residence. The Journal of Social Psychology, 125(6), 689-694. doi:10.1080/00224545.1985.9713540

Bochner, S., McLeod, B. M., \& Lin, A. (1977). Friendship patterns of overseas students: A functional model. International Journal of Psychology, 12(4), 277-294. doi:10.1080/00207597708247396

Brebner, L. H. (2008, December). Intercultural interactions in a New Zealand university: Pakeha and Asian perspectives. Paper presented at ISANA International Conference, Auckland, New Zealand.

Brown, L. (2009a). International education: a force for peace and cross-cultural understanding? Journal of Peace Education, 6(2). 209-224. doi:10.1080/17400200903086672

Brown, L. (2009b). An ethnographic study of friendship patterns of international students in England: An attempt to recreate home through conational interaction. International Journal of Educational Research, 48(3), 184-193. doi: 10.1016/j.ijer.2009.07.003

Church, A. (1982). Sojourner adjustment. Psychological Bulletin, 91, 540-572. doi:10.1037/0033-2909.91.3.540

Clark, B. (1986). The higher education system: Academic organization in cross national perspective. Los Angeles, CA: University of California Press.

Cushner, K., \& Karim, A. (2004). Study abroad at university level. In: D. Landis, J. Bennett and M. Bennett, Eds. Intercultural training. London, Sage. 
Engle, L., \& Engle, J. (2003). Study abroad levels: Toward a classification of program types. Frontiers: The Interdisciplinary Journal of Study Abroad, 9, 1-20.

Fernández, S., Fernández, S., \& Vaquero, A. (2007). Proyección internacional de los sistemas de educación superior de américa latina y el Caribe. Revista Iberoamericana de Educación, 45, 159-175.

Furnham, A., \& Alibhai, N. (1985). The friendship networks of foreign students: A replication and extension of the functional model. International Journal of Psychology, 20, 709-722. doi:10.1080/00207598508247565

Gareis, E. (2012). Intercultural friendship: Effects of Home and Host Region. Journal of International and Intercultural Communication, 5(4), 309-328. doi:10.1080/17513057.2012.691525

Giavi, P. V., Iglesia, G., \& Iglesia, J. (2008). Estudiantes internacionales: Una oportunidad para la Argentina. Gobierno de la Ciudad de Buenos Aires Ministerio de Desarrollo Economico. EduArgentina.

Goldstein, S. B. (2015). Predictors of preference for the exported model of study abroad. Frontiers: The Interdisciplinary Journal of Study abroad, 26, 1-16.

Hadis, B. F. (2005). Gauging the impact of study abroad: how to overcome the limitations of a single-cell design. Assessment \& Evaluation in Higher Education, 30(1), 3-19. doi:10.1080/0260293042003243869

Hall, E. T. (1959). The Silent Language. NY: Anchor Books.

Hendrickson, B., Rosen D., \& Aune, R. K. (2011). An analysis of friendship networks, social connectedness, homesickness, and satisfaction levels of international students. International Journal of Intercultural Relations, 35, 281-295. doi:10.1016/j.ijintrel.2010.08.001

Hoffa, W. W. (2007). A History of US Study Abroad: Beginnings to 1965. A Special Publication of Frontiers: The Interdisciplinary Journal of Study abroad and the Forum on Education Abroad.

Johnson, J. P., Lenartowicz, T., \& Apud, S. (2006). Cross-cultural competence in international business: Toward a definition and a model. Journal of International Business Studies, 37, 525-543. doi:10.1057/palgrave.jibs.8400205

Kim, Y. Y. (2001). Becoming Intercultural: An integrative theory of communication and cross-cultural adaptation. Thousand Oaks, CA: Sage.

Maundeni, T. (2001). The role of social networks in the adjustment of African students to British society: Student's perceptions. Race Ethnicity and Education, 4, 253-276. doi: 10.1080/13613320120073576

McPherson, A. (2006). Intimate Ties, Bitter Struggles: The United States and Latin America since 1945. Washington, D.C.: Potomac Books.

Ministerio de Educación de Argentina (MEA). (2010). Promoción de la Universidad. Retrieved from: http://www.me.gov.ar/spu/guia_tematica/promocion/promocion_inicio.html.

Menard, S. (2002). Longitudinal Research Series, $2^{\text {nd }}$ ed. Quantitative Applications in the Social Sciences, vol. 67. Thousand Oaks, CA: Sage.

Miles, M., \& Huberman, M. (1994). Qualitative Data Analysis. An Expanded Sourcebook. $\quad$ Thousand Oaks, CA: Sage.

Montgomery, C., \& McDowell, L. (2009). Social networks and the international student experience: An international community of practice? Journal of Studies in International Education, 13(4), 455466. doi:10.1177/1028315308321994

Neri, F., \& Ville, S. (2008). Social capital renewal and the academic performance of international students in Australia. The Journal of Socio-Economics, 37, 1515-1538. doi:10.1016/j.socec.2007.03.010

Nogueira, R. M., \& Góngora, N. (2000). Evaluación de la gestión universitaria. Report prepared for the National Evaluation and Accreditation Commission. Argentina: CONEAU.

Norris, E. M., \& Dwyer, M. (2005). Testing assumptions: The impact of two study abroad program models. Frontiers: The Interdisciplinary Journal of Study abroad, 11, 121-142. 
Peacock, N., \& Harrison, N. (2009). "It's so much easier to go with what's easy: "Mindfulness" and the discourse between home and international students in the United Kingdom. Journal of Studies in International Education, 13(4), 487-508. doi:10.1177/1028315308319508

Pedersen, P. J. (2009). Teaching towards an ethnorelative worldview through psychology study abroad. Intercultural Education, 20, (73-86). doi: 10.1080/14675980903370896

Pitts, M. J. (2009). Identity and the role of expectations, stress, and talk in short-term student sojourner adjustment: An application of the integrative theory of communication and crosscultural adaptation. International Journal of Intercultural Relations, 33, 450-462. doi:10.1016/j.ijintrel.2009.07.002

Pruitt, F. J. (1978). The adaptation of African students to American society. International Journal of Intercultural Relations, 2, 90-118. doi:10.1016/0147-1767(78)90030-5

Quacquarelli Symonds Limited (QS). (2015). QS Latin American University Rankings 2015. Retrieved from http://www.topuniversities.com/university-rankings/latam-university-rankings/2015

Rienties, B., Nanclares, N. H., Jindal-Snape, D., \& Alcott, P. (2013). The role of cultural background and team divisions in developing social learning relations in the classroom. Journal of Studies in International Education, 17, 332-353. doi:10.1177/1028315312463826

Rodman, R., \& Merrill, M. (2010). Unlocking study abroad potential: Design models, methods and masters. In Hoffa, W. W., \& DePaul, S. C, A History of US Study Abroad: 1965- Present (pp.199251). Carlisle: PA: Frontiers: The Interdisciplinary Journal of Study Abroad.

Rogers, E. M., \& Kincaid, D. L. (1981). Communication networks: Toward a new paradigm for research. New York: Free Press.

Rohrlich, B. F., \& Martin, J. N. (1991). Host country and reentry adjustment of student sojourners. International Journal of Intercultural Relations, 15, 163-182. doi:10.1016/0147-1767(91)90027-E

Saavedra, A. (2012, August 7). Tenemos que repensar la Universidad. Interview with Michael Buroway, president of the International Sociology Association. Página/12 online.

Salisbury, M. H., Paulsen, M. B., \& Pascarella, E. T. (2010). To see the world or stay at home: Applying an integrated student choice model to explore the gender gap in the intent to study abroad. Research in Higher Education, 51, 615-640. doi:10.1007/s11162-010-9171-6

Savicki, V. (2010). An analysis of the contact types of study abroad students: The peer cohort, the host culture and the electronic presence of the home culture in relation to readiness and outcomes. Frontiers: The Interdisciplinary Journal of Study abroad, 19, 61-86.

Sawir, E., Marginson, S, Deumert, A., Nyland, C., \& Ramia, G. (2008). Loneliness and international students: An Australian study. Journal of Studies in International Education, 12(2), 148-180. doi:10.1177/1028315307299699

Smink, V. (2013). Argentina, un imán para los estudiantes universitarios. BBCMundoonline, Retrieved from: http://www.bbc.co.uk/mundo/ noticias/2013/05/130524_argentina_ estudiantes_extranjeros_vs.shtml

Sudweeks, S., Gudykunst, W. B., Ting-Toomey, S., \& Nishida, T. (1990). Developmental themes in Japanese-North American interpersonal relationships. International Journal of Intercultural Relations, 14, 207-233. doi:10.1016/0147-1767(90)90006-I

Teddlie, C., \& Yu, F. (2007). Mixed Methods Sampling: A typology with examples. Journal of Mixed Methods Research, 1, 77-100. doi:10.1177/2345678906292430

Tian, M. \& Lowe, J. A. (2013). Intercultural identity and intercultural experiences of American Students in China. Journal of Studies in International Education, $X X(X), 1-17$. doi:10.1177/1028315313496582

Trice, A. D., \& Elliot, J. (1993). Japanese students in America: College friendship patterns. Journal of Instructional Psychology, 20(3), 262-265. 
Trice, A. G. (2007). Faculty perspectives regarding graduate international students' isolation from host national students. International Education Journal, 8(1), 108-117.

US Department of Education. (2016). FAFSA Federal School Code search. Retrieved from https:// fafsa.ed.gov/FAFSA/app/schoolSearch? locale=en_EN

US State Department. (2011). 100,000 Strong in the Americas. United States Department of State, Bureau of Western Hemisphere Affairs. Retrieved from: http://www.state.gov/p/wha/rt/100k/index.htm

Vande Berg, M. (2007). Intervening in the learning of U.S. students abroad. Journal of Studies in International Education, 11, 392-399. doi: 10.1177/1028315307303924

Vande Berg, M. J., Balkcum, A., Scheid, M., \& Whalen, B. J. (2004). The Georgetown University Consortium project: A report from the halfway mark. Frontiers: The Interdisciplinary Journal of Study Abroad, 10, 1-16.

Vande Berg, M., Connor-Linton, J., \& Paige, M. P. (2009). The Georgetown Consortium Project: Interventions for student learning abroad. Frontiers: The Interdisciplinary Journal of Study Abroad, 18, 1-75.

Ward, C., \& Kennedy, A. (1993). Where's the "culture" in cross-cultural transition? Comparative studies of sojourner adjustment. Journal of Cross-Cultural Psychology, 24, 221-249. doi: $10.1177 / 0022022193242006$

Wasserman, S., \& Faust, K. (1994). Social network analysis: methods and applications. New York: Cambridge University Press.

Wiarda, H. J. (1981). The ethnocentrism of the social science implications for research and policy. The Review of Politics, 43(2), 163-197. doi: 10.1017/S0034670500029715

Woolf, M. (2007). Impossible things before breakfast: Myths in education abroad. Journal of Studies in International Education, 11, 496-509. doi: 10.1177/1028315307304186

Ying, Y. W. (2002). Formation of cross-cultural relationships of Taiwanese international students in the United States, Journal of Community Psychology, 30(1), 45-55. doi: 10.1002/jcop.1049

Zhang, J., \& Goodson, P. (2011). Predictors of international students' psychosocial adjustment to life in the United States: A systematic review. International Journal of Intercultural Relations, 35, 139162. doi:10.1016/j.ijintrel.2010.11.011 


\section{Appendix: Interview References}

\begin{tabular}{|c|c|c|c|c|c|}
\hline Ref & Country & Age & Sex & University & Language \\
\hline 1 & USA & 21 & Female & Private & Spanish \\
\hline 2 & Germany & 21 & Female & Private & Spanish \\
\hline 3 & Colombia & 21 & Male & Private & Spanish \\
\hline 4 & Brazil & 22 & Male & Private & Spanish \\
\hline 5 & Germany & 23 & Female & Private & Spanish \\
\hline 6 & USA & 21 & Female & Private & Spanish \\
\hline 7 & Finland & 23 & Female & Private & English \\
\hline 8 & Germany & 25 & Male & Private & Spanish \\
\hline 9 & Colombia & 20 & Female & Private & Spanish \\
\hline 10 & Switzerland & 26 & Male & Private & Spanish \\
\hline 11 & Spain & 24 & Male & Private & Spanish \\
\hline 12 & USA & 20 & Female & Private & Spanish \\
\hline 13 & USA & 20 & Female & Private & Spanish \\
\hline 14 & Canada, Quebec & 21 & Female & Private & Spanish \\
\hline 15 & Austria & 23 & Male & Private & Spanish \\
\hline 16 & Czech Republic & 22 & Female & Private & Spanish \\
\hline 17 & USA & 20 & Female & US Program & Spanish \\
\hline 18 & USA & 20 & Female & US Program & Spanish \\
\hline 19 & USA & 20 & Male & US Program & Spanish \\
\hline 20 & Mexico & 25 & Female & Private & Spanish \\
\hline 21 & France & 22 & Female & Private & Spanish \\
\hline 22 & Spain & 21 & Female & Private & Spanish \\
\hline 23 & Spain & 22 & Female & Private & Spanish \\
\hline 24 & France & 23 & Male & Public & Spanish \\
\hline 25 & USA & 20 & Male & US Program & English \\
\hline 26 & USA & 20 & Female & US Program & English \\
\hline 27 & USA & 19 & Male & US Program & English \\
\hline 28 & USA & 20 & Female & US Program & Spanish \\
\hline 29 & USA & 21 & Male & US Program & Spanish \\
\hline 30 & USA & 21 & Female & US Program & English \\
\hline 31 & USA & 21 & Male & US Program & English \\
\hline 32 & Norway & 25 & Female & Public & Spanish \\
\hline 33 & Germany & 24 & Female & Public & Spanish \\
\hline 34 & Brazil & 32 & Female & Public & Spanish \\
\hline
\end{tabular}

